\title{
PENETRATING KERATOPLASTY FOR TREATMENT OF BULLOUS
} KERATOPATHY

\section{Snezhana V. Murgova, Chavdar B. Balabanov}

\begin{abstract}
Department of Eye Diseases, Medical University - Pleven, Bulgaria
\end{abstract}

\section{Corresponding Author:}

Snezhana V. Murgova

Eye Clinic UMBAL "Dr. G. Stranski”

91, Gen. Vladimir Vazov str.

Pleven, 5800

Bulgaria

e-mail: snejana_murgova@yahoo.com

Received: October 28, 2015

Revision received: November 04, 2015

Accepted: November 30, 2015

\section{Summary}

The aim of the retrospective study was to analyze results after penetrating keratoplasties in patients with bullous keratopathy. The study included 60 patients with bullous keratopathy who underwent penetrating keratoplasty for the period 1990-2011, at the Eye Clinic of Pleven University Hospital. The average age of patients was 67 years (range 29-84 years). Additional risk factors were registered in $22.67 \%$ of the patients. Early postoperative complications occurred in $56.79 \%$. In the early postoperative period, $81.31 \%$ of the patients had clear graft and improvement of visual acuity was achieved in $83.77 \%$. In the late postoperative period, the graft failed in $28.95 \%$ of the patients. These results suggest that bullous keratopathy is an important complication after cataract surgery, and improvement of vision is possible only with keratoplasty.

Key words: penetrating keratoplasty, bullous keratopathy

\section{Introduction}

Bullous keratopathy (BK) is a disorder caused by endothelial dysfunction and characterized by stromal edema with epithelial and subepithelial bullae. In advanced cases, retrocorneal fibrous membrane and corneal vascularization can occur. Patients present with decreased vision, sensation of a foreign body, photophobia and severe pain when epithelial bullae rupture.

BK is a main complication in all types of cataract surgery, due to a number of factors such as corneal distortion, ricocheting of nuclear fragments, intraocular lens (IOL) contact, and release of free radicals [1].

Treatment of BK is conservative - hyperosmotic drops, therapeutic soft contact lens. If medical treatment fails, corneal transplantation (penetrating or posterior lamellar) is a treatment of choice to restore vision and decrease pain. Unfortunately, sometimes the patients must wait for a long time until the transplantation is performed, and in other cases such an intervention is not recommended or visual potential is poor. For this reason other interventions were attempted in order to improve symptoms - amniotic membrane transplantation, conjunctival covering, and anterior stromal puncture, corneal cross linking [2-4]. 
The aim of the study was to analyze the results after penetrating keratoplasties in patients with bullous keratopathy.

\section{Material and Methods}

This retrospective study included 60 patients with bullous keratopathy, who underwent penetrating keratoplasty. The surgery was performed by one surgeon between 1990 and 2011 at the Eye Clinic, Pleven University Hospital. Data was collected on age, sex and additional risks factors before surgery.

Standard penetrating keratoplasty was performed in all the cases, using manual trephines for donor and recipient cornea. The donor cornea was sutured to the recipient, using

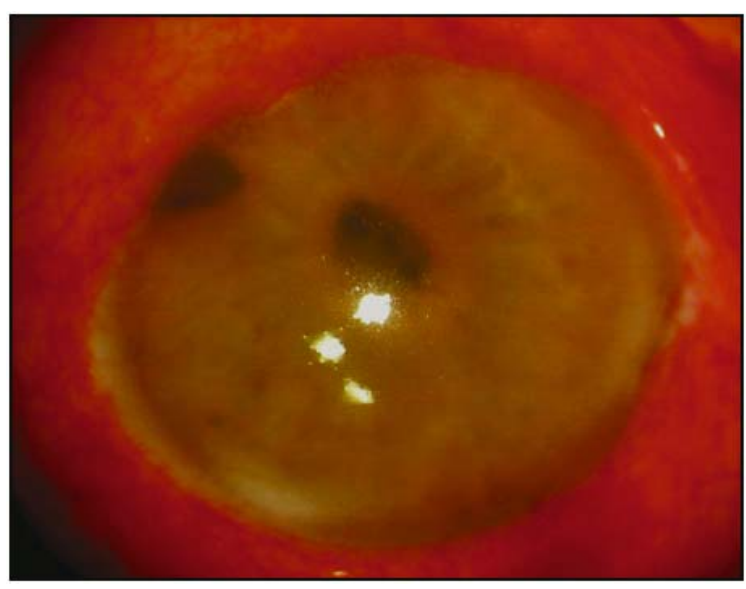

Figure 1. Bullous keratopathy in a patient with trabeculectomy and IOL

In two patients, amniotic membrane was transplanted but because of the persistent complaints of pain and irritation, keratoplasty was performed 3 months later.

In 24 cases $(40 \%)$ additional intraocular interrupted sutures, 10/0 nylon. If necessary, additional procedures were undertaken - anterior vitrectomy, iris suture, or synechotomy. Graft status, visual acuity and complications were followed up and documented.

\section{Results}

The study group included 60 patients (35 men and 25 women). The median age was 67 years (range 29- 84 years). Additional risk factors were registered in $22.67 \%$ of the patients, including preoperative glaucoma (after trabeculectomy Figure 1), in 10 cases $(16.7 \%)$; corneal vascularization (Figure 2) in 6 patients $(10 \%)$ and one patient $(1.7 \%)$ with blepharitis.

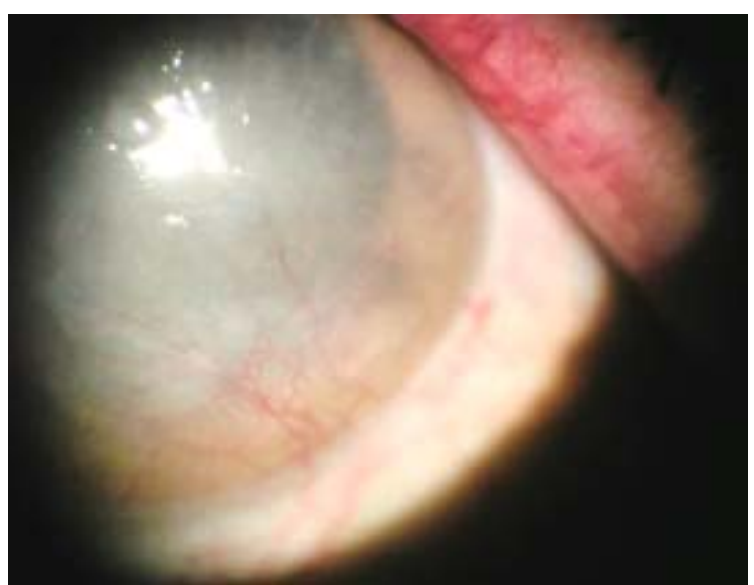

Figure 2. Neovascularization in a patient in patient with bullous keratopathy

surgical procedures were performed. The most frequent procedures were: suture of iris - in 50\% of the cases, anterior vitrectomy - in $32.35 \%$, implantation of intraocular lens (IOL) - in 8.82\% and membranectomy - in $8.82 \%$ (Figure 3 ).
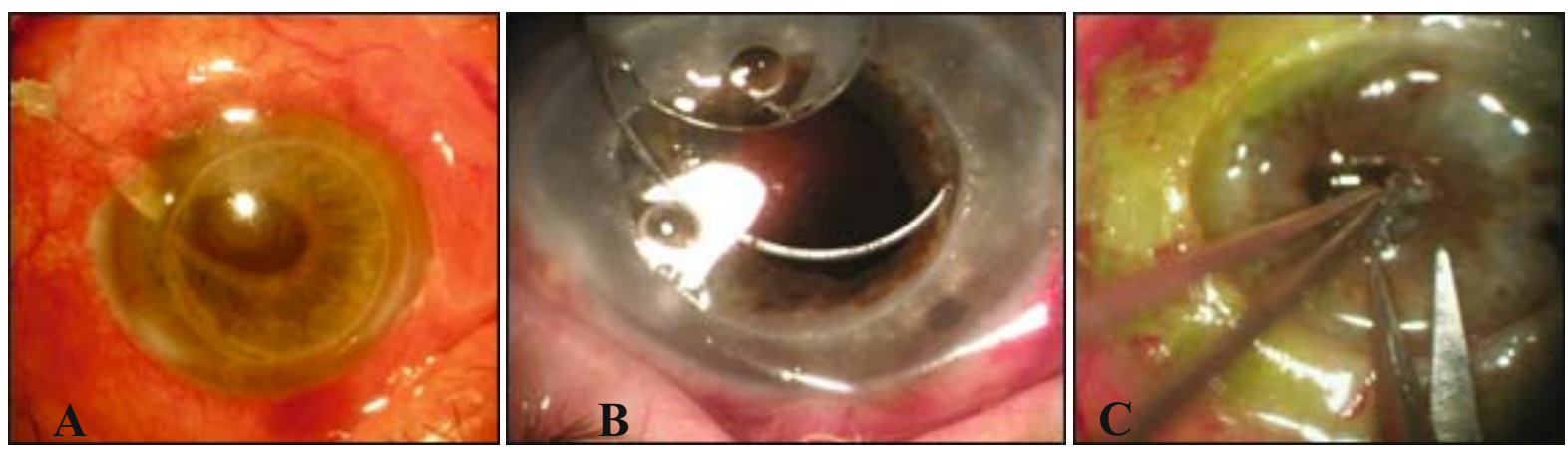

Figure 3. Additional intraocular surgical procedures. A - anterior vitrectomy; B - IOL implantation; $\mathrm{C}-$ membranectomy 
Early postoperative complications occurred in $56.79 \%$ of the cases. The most common complications were corneal edema $(30.77 \%)$ and shallow anterior chamber $(26.92 \%)$.

In the early postoperative period, $81.31 \%$ patients had clear grafts and $83.77 \%$ had improvement of visual acuity. Visual acuity above 0.1 was diagnosed in $26.01 \%$ of the patients.

In the period before suture removal (average $8-9$ months), the grafts were clear in $58.88 \%$ of the cases (Figure 4).

A

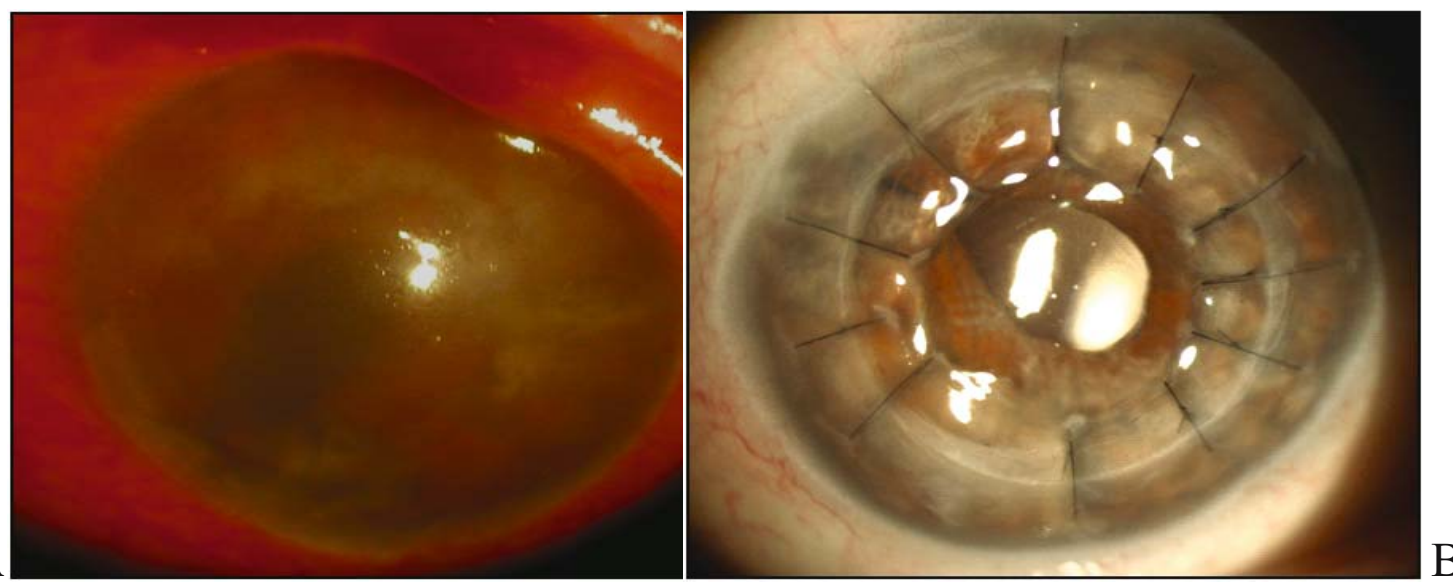

Figure 4. A patient with bullous keratopathy. A - before operation; B - 7 months after keratoplasty

In the late postoperative period, mainly patients with any type of complaints were followed up. During this period the graft failed in $28.95 \%$ of the patients. In ten cases, one re-graft was performed, in two cases - two re-grafts, and in two patients - three re-grafts. Figures 5 and 6 show the Kaplan-Mayer graft survival rate for the first year and to the end of the study.

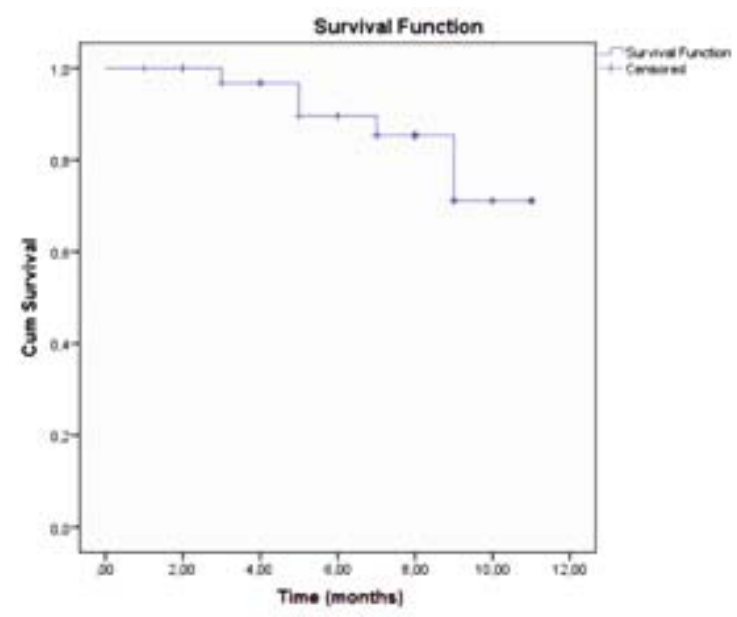

Figure 5. Kaplan-Meier graft survival with BK for the first year

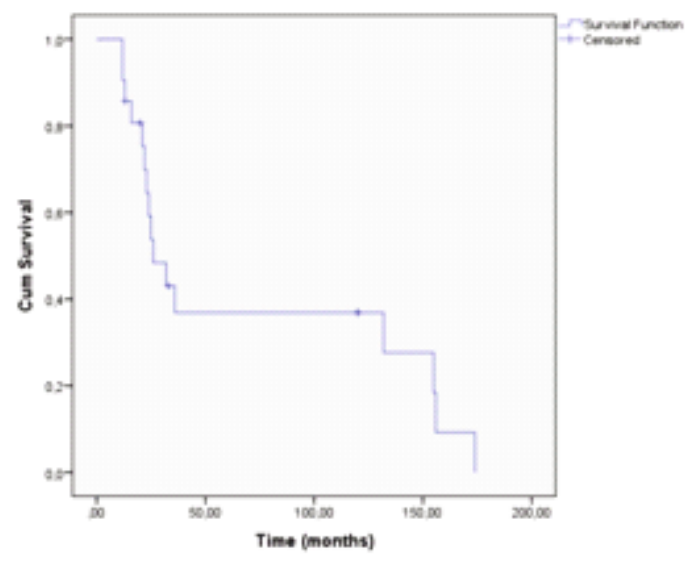

Figure 6. Kaplan-Meier graft survival rates rates in patients in patients with BK at the end of the study

\section{Discussion}

Bullous keratopathy is a main complication of cataract surgery. The purposes of treatment are to reduce pain and improve vision when possible. Treatments include medical and surgical options, depending on the severity of symptoms, cause of bullous keratopathy and potential for visual improvement.

In eyes with poor visual potential, the options of treatment are bandage contact lenses, anterior stromal puncture, conjunctival flaps. Amniotic 
membrane transplantation (AMT) is also considered. A number of studies have reported $80-90 \%$ relief in symptoms after amniotic membrane transplantation. In our study, two cases had recurrent pain after AMT, due to recurrent keratopathy $[5,6]$.

When there is good visual potential, keratoplasty is the only available curative treatment. The first series of keratoplasties for bullous keratopathy was reported by Fine in 1978 [7]. Recently, the application of endothelial keratoplasty has been increasing. It is considered as a promising alternative to penetrating keratoplasty. To perform endothelial keratoplasty, adequate visualization and deep anterior chamber are needed [8]. When the cornea is not sufficiently transparent and the anterior chamber is shallow, the treatment of choice is penetrating keratoplasty.

In this study, we registered a large percentage of complications. They were often due to the additional intraoperative interventions. In the late postoperative period, $29 \%$ of grafts failed, and ten cases required re-graft. BK has been found to be the leading cause for repeat keratoplasty [9$11]$.

In the early postoperative period vision above 0.1 was diagnosed in $27 \%$ of our cases. This outcome was associated not only with the status of the graft, but with other reasons as well, such as the state of the anterior segment, damage to the macula, atrophy of optic nerve etc. [12].

\section{Conclusion}

Bullous keratopathy is an important complication after cataract surgery and a leading indication for keratoplasty. There are methods of treatment that alleviate pain, discomfort, reduce ocular inflammation, and promote epithelial healing and resolution of bullae. They are suitable for patients with poor visual prognosis. Improvement of vision is possible only with keratoplasty.

\section{References}

1. Bourne RR, Minassian DC, Dart JK, Rosen P, Kaushal S, Wingate N. Effect of cataract surgery on the corneal endothelium: modern phacoemulsification compared with extracapsular cataract surgery. Ophthalmology. 2004;111(4):679-85.
2. Stefaniu GI, Chiotoroiu SM, Secureanu FA, Purcarea VL, Zemba M. Use of amniotic membrane in bullous keratopathy palliative care. $\mathrm{J}$ Med Life. 2014;7(Spec Iss 2):88-91.

3. Knezović I, Dekaris I, Gabrić N, Cerovski J, Barisić A, Bosnar D, Rastegorac P, Parać A. Therapeutic efficacy of $5 \% \mathrm{NaCl}$ hypertonic solution in patients with bullous keratopathy. Coll Antropol. 2006;30(2):405-8.

4. Gonçalves ED, Campos M, Paris F, Gomes JA, Farias CC. Bullous keratopathy: etiopathogenesis and treatment. Arq Bras Oftalmol. 2008;71(6 Suppl):61-4.

5. Pires RT, Tseng SC, Prabhasawat P, Puangsricharern V, Maskin SL, Kim JC, Tan DT. Amniotic Membrane Transplantation for Symptomatic Bullous Keratopathy. Arch Ophthalmol. 1999;117(10):1291-7.

6. Mejía LF, Santamaría JP, Acosta C. Symptomatic management of postoperative bullous keratopathy with nonpreserved human amniotic membrane. Cornea. 2002;21(4):342-5.

7. Sugar A. An analysis of corneal endothelial and graft survival in pseudophakic bullous keratopathy. Trans Am Ophthalmol Soc. 1989;87: 62-801.

8. Röck D, Röck T, Bartz-Schmidt KU,Yoeruek E. Descemet membrane endothelial keratoplasty in cases with existing scleral-sutured and iris-sutured intraocular lenses. BMC Ophthalmology [Internet]. 2014 [cited 2015 oct 25];14(6):[about 4 p.]. Available from: http://www.biomedcentral.com/1471-2415/14/6

9. Zare M, Aslani M, Azimzadeh A, Esfandiari H, Valizadeh M. Indications and outcomes of repeat penetrating keratoplasty. Iran J Ophthalmol. 2011;23(2):44-50.

10. Waltman S. Penetrating Keratoplasty for Pseudophakic Bullous Keratopathy. Arch Ophthalmol. 1981;99(3):415-6.

11. Al-Yousuf N, Mavrikakis I, Mavrikakis E, Daya SM. Penetrating keratoplasty: indications over a 10 year period. Br J Ophthalmol. 2004;88(8):9981001.

12. Schraepen P, Koppen C, Tassignon MJ. Visual acuity after penetrating keratoplasty for pseudophakic and aphakic bullous keratopathy. J Cataract Refract Surg. 2003;29(3):482-6. 